\title{
PSYCHOLOGY OF THE HAND.
}

Essai sur la psychologie de la main. N. VAschide. Preface by Charles Richet. Paris, Marcel Rivière, igo9. Pp. $\mathrm{v}+488$.

The impression produced by reading this long essay upon the psychology of the hand is a curious one. Partly, the effect is a deepening consciousness of the significance of this small organ; partly, the feeling is one of intense appreciation of the author's preoccupation with his subject, an appreciation too of his erudition and versatility evinced in a strange intermixture of science and poetry.

Vaschide has levied contributions from many a field in his attempt to make an exhaustive study of his subject. The canons of art, the dissections of the anatomist, the intuitions of the chiromancer, the measurements of the anthropologist and criminologist, as well as the studies of the pathologist and the psychologist, all are utilized. One cannot bring to bear upon the author's work the criticism he himself passes upon contemporary psychological research, that it lacks atmosphere and setting, for his book is very rich in literary and historical references. If, on the other hand, certain unsolved problems are treated somewhat summarily, this summary treatment may be pardoned when one considers the range covered by the book. Revision of the work was, moreover, precluded by the untimely death of the author. Here and there are to be found unfinished sections, one of these proving, unfortunately, to be the chapter on the 'Motor Image' where the reviewer had hoped to find the author bringing together in some theoretical way the facts he had accumulated on the rôle of movement in the mental life, since he conceives the hand to be the very organ of the muscular sense.

Preceding the more scientific portion of the book is a consideration, historical and descriptive, of chirognomy and chiromancy, the first seeking to read character from the lines and contours of the hand, the second seeking by the same means to fathom human destiny.

The author gives a running summary, with no critical comment, of the principal facts noted in the study of the hand with regard to palm, fingers, lines of the hand, various so-called mounts, coloration, and finger nails.

From this he passes to a consideration of the artistic canon of the hand, the proportion between its parts recognized as most harmonious by men who have given particular attention to the beauty of the human body. The hand in works of art constitutes one of the most interesting as well as one of the most richly illustrated chapters of the book. Beginning with the Egyptian hand, small, narrow, spatulate, 
Vaschide traces the evolution to the beautifully modelled hand of eighteenth century art. The early treatment is conventional, monotonous; the hand is dominated by the arm and the gesture. Early Greek art, while failing to individualize the hand, begins to give attention to details, and Greek art at its height works out the individuality of the hand completely, exhibiting in Apollo the 'psychic' hand, in Mercury the 'practical' hand, in Aphrodite the 'artistic' hand. With early Christian art the stereotyped hand and gesture return. Gothic art brings a renewal of attention to details with the introduction into art of the 'bony' hand. Italian art of the sixteenth century shows all the beauties of the Greek classic period in its treatment of the hand, plus a certain humanising element, as witness the beautiful hand of Jeanne d'Aragon as painted by Raphael. For perfection in treatment of the hand, Vaschide inclines to give the laurel to French art of the eighteenth century.

Thus, in its artistic evolution, one sees the hand grow from a vague block-outline into a living personality. Little by little, the fingers open out and give life to the gesture; little by little the hollow of the hand is revealed with its delicate inner tracery until at last the hand is discovered as that organ of the body most expressive of its vitality and mobile intelligence.

Under the anatomo-physiology of the hand, the author describes its ossature, musculature, innervation, and vasculature, emphasizing throughout the marvellous complexity of its structure and the resulting complexity of function. Variations in the blood-volume of the hand in correlation with emotional changes are cited and the means used in registration of the digital pulse mentioned, with a summary citation of the principal researches that have been made upon the psychophysiological criterium of vascular reactions.

But the hand is not only the most flexible instrument conceivable; it is an organ of sense as well as an organ of movement. A noncritical summary follows of the psycho-physiological researches that have been carried on upon the hand as a sense-organ. The summary is fairly exhaustive in a schematic way, although there are some noticeable omissions, - no mention, for instance, occurs of cutaneous after-images. The literary references are also incomplete in certain respects.

The varying sensitivity of different parts of the hand is accounted for in physiological terms. The determination of the lines of the hand by its muscular-tendinous demarcations is noted. Dependence of tactile sensitivity and tactile localization upon mobility of the part in 
question and upon exercise is proved with mention of the rôle played by the sensation of pressure received in connection with the fingernails. Individual variation in tactile sensitivity receives attention, particularly the sensitivity of man and woman, of criminals, and of the blind. The discussion includes also consideration of the following subjects : Linear stimulation in comparison with double-point stimulation; perception of movement on skin relative to sensitivity of tested portion; modification of tactile sensitivity through heat, cold, and drugs ; relation of tactile sensitivity to tension of skin ; dissociation of tactile sensations; allochiria, in which a touch on one side of the body is felt and located on the other; Weber's sensory circles; the doctrine of local signs, with citation of various explanations that have been given; common tactile illusions, as that of Aristotle; left and right hand excursions after a model; tactile estimation of thickness; influence of education of voluntary motility upon sensitivity ; touch sensibility as increased by the posture of hand which favors rapidity of finger-movement; differentiation of tactile sense-organs and correlated differentiation of sensations.

A separate chapter is devoted to finger-prints. Their use among primitive and savage peoples, the early observations of Purkinje and Alix, the employment of them by Sir William Herschell in his administrative work in India, are noted as preliminary to Galton's investigation.

Féré, who found in the degenerates that he examined dissimilarity in the pattern from finger to finger and from hand to hand, considered such asymmetry to be a frequent and important mark of degeneracy. Vaschide, following Féré, is inclined to attribute higher anthropological significance to various digital patterns than does Galton, who values them chiefly for purposes of identification.

The pathology of the hand affords a wide field of study. Frequently an inspection of this member aids in diagnosis of disease. The illusion of the phantom-hand and the various forms it may assume are described, the author urging that the psychic factor in such an illusion must be recognized as well as the peripheral cause. Writer's cramp is considered at length, and other occupational cramps are cited. The study of the mechanism of the affection raises the question whether it is due to peripheral causes or to cerebral fatigue. The fact that the muscles of the hand may be used in coördinations other than those of writing is cited in support of the latter position by Duchenne, whom Vaschide is inclined to follow.

Vaschide distinguishes two elements in the situation: $(x)$ the 
automatic physiological element, that of the habit of systematic coördination of a certain number of movements; and (2) the psychic act, the functional play of attention. Writing, he conceives, is so frequently subject to functional disorders, because of the interplay here of a highly automatized function and a high degree of mental activity. For this reason he holds that writer's cramp should not be confounded with other functional cramps, although it undoubtedly possesses elements in common.

The hand from the anthropological point of view involves a detailed comparison of the hand of man with that of the animals nearest him in the zoölogical order. Instructions are given as to the methods to be used in taking accurate measurements of the human hand. From the data already collected it is concluded that the relative length of the hand is a differential characteristic of some importance in ethnic study. Europeans have small hands; the yellow races, large ones; the black race a hand intermediate in size between these two others. The correlation of the proportions of the hands with the cephalic index, color of hair, habitat, and profession is also considered.

There follows an eloquently phrased section upon the revelations exhibited in the hand-clasp and gesture of the sane and the insane, with reference to the social recognition of the value of the hand. Right-handedness is dismissed somewhat summarily with certain interesting allusions to racial customs.

The chapter on the motor image is, as mentioned above, incomplete; unfortunately so, as at this point the author might properly have discussed the question of the relation of consciousness and movement. An historical sketch is given of the gradual recognition of the distinction between tactile and muscular sensibility. The problem of an innervation sense is also touched upon briefly. Vaschide affirms the existence of an independent muscular sensibility, whose principal organ is found in the hand.

The book is interesting, and its value is increased by the fact that the author had himself carried out researches upon many of the subjects treated.

June E. Downey.

UNIVERSITY OF WYOMING.

Control Processes in Modified Hand-Writing: An Experimental Study. June E. Downey. Stud. from the Psychol. Lab. of the Univ. of Chicago. Psychological Monographs, No. 37. Published by the Psychological Review. Pp. vii +148 .

The immediate purpose of this investigation was to determine in some detail the interplay of visual, auditory and kinæsthetic processes 